\title{
DIAGNOSTICS OF GEARS AND COMPRESSORS BY MEANS OF ADVANCED AUTOMATIC SYSTEM
}

\author{
Jerzy TOMASZEWSKI*, Jacek RYSINSKI* \\ *Faculty of Mechanical Engineering and Computer Science, Department Of Mechanical Engineering Fundamentals, \\ University of Bielsko-Biala, ul. Willowa 2, 43-300 Bielsko-Biala, Poland \\ jtomaszewski@ath.bielsko.pl, irysinski@ath.bielsko.pl
}

\begin{abstract}
In the present paper, the diagnostics problems of gears and air-compressors are discussed. The diagnostics has been performed by means of wireless system WiViD. This system is a unique design solution, in which several functions are divided and performer by two separate devices. The mentioned device functions are as follows: data handling, processing, their analysis and presentation. In the paper, own measurement procedures were created, checked and presented. The evaluation of technical conditions of some devices was done based upon the registered diagnostic symptoms, which were compared with the allowable limits.
\end{abstract}

Key words: Gears, Air-Compressor, Diagnostic

\section{INTRODUCTION}

Nowadays, diagnostics is a common practice aiming for an evaluation of technical state of devices and elements of the drive systems working in the industrial technological lines. Rapid development of this method was possible due to the fact that wide range of modern devices is available on the market. By means of these devices, the diagnostics activities - which allow for adequate evaluation of machine state - can be performed in real time. Among the devices which are currently available, the machine diagnostic system named WiViD, produced by Polish firm Alitec from Łódź, could be easily and effectively used.

System WiViDTM is a unique design solution, in which several functions is divided and performer by two separate devices. The mentioned device functions are as follows: data handling, processing, their analysis and presentation.

The basic executive element of the system is: wire-less, multicanal measurement board mounted inside the shock-proof, ergonomic housing. The measurement head allows for measurements of vibrations in three directions, within the very broad frequency band $(0.4 \mathrm{~Hz}-20 \mathrm{kHz})$. The potential range of application is even extended via a possibility of connection of an external gauge CLPS type (i.e. vibration and forces gauge as well as microphone), additional there is the connection of signal of phase indicator. All measurements are synchronically performed. The device could be utilized as a mini infra-red (thermo-vision) camera, displaying a thermal image of point resolution $16 \times 4$, within the temperature range $50^{\circ} \mathrm{C}$ do $300^{\circ} \mathrm{C}$.

Second element of the system could be: a smartphone or a tablet - working under control of the operational system Android (version 4.x). The specialized software gathers measurement information in the mobile data base. After conversion, they are presented in a clearly way on the screen. The software integrates the set tools for an evaluation of technical state of such machine parts like e.g. bearings, elements of drive systems and transmissions.

In the paper, the examples of an application of the afore-men- tioned device for diagnostics of compressors and gears are described.

The methodology of evaluation of technical state of a gear within its working time was prepared. In consequence, it was prepared several measurement rules e.g.: the procedure of determination of thresholds for point estimates of vibration signal measured on the gear bearing housings as well as the procedure of evaluation of technical state based upon the earlier determined thresholds.

\section{DIAGNOSTICS OF SCREW COMPRESSORS}

Screw compressors (Fig. 1.) are devices dedicated for compression of gases. The processof compression of gas (in our case i.e. air) consists in diminishing of the space between rotating screws - from the suction (intake) connector holes up to exhaust holes (outlet).

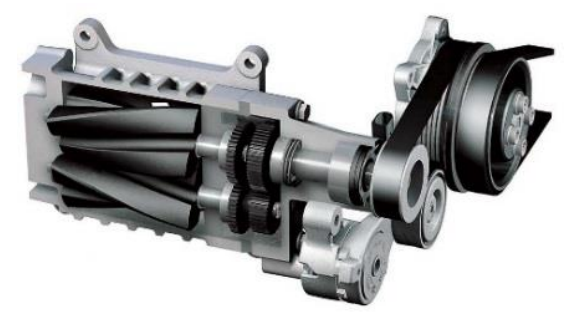

Fig. 1. Screw compressor

The value of compression, in these compressors, depends on their design (construction), moreover the efficiency of the compression element itself depends (mainly) upon the tightness level achieved between both screws as well as between screws and housing. The basic parts of the screw element are rotors - in Polish so called - male and female ones, rotating in opposite directions when simultaneously the space between them and the housing consequently diminishes. 


\subsection{Diagnostics of compressors: approval and run}

In case of approval diagnostics, evaluation of quality can be performed in accordance with the standard VDI 3836 (2012), which is subsidiary to the standard ISO 10816-3 (2009). According to the standard VDI 3836, the compressors can be divided into 4 groups:

- Group no 1. Screw compressors with a sliding bearing, with gears. The compressors belonging to this group are utilized for compression of ordinary process gases ( $P \geq 55 \mathrm{~kW})$.

- Group no 2. Screw compressors, equipped with rolling and sliding bearing as well as gears. Air, oil-less compressors are usually classified as belonging to this group ( $P \geq 37 \mathrm{~kW})$.

- Group no 3. Screw compressors, without gears. The compressors filled by oil usually belong to this group ( $P \geq 55 \mathrm{~kW})$.

- Group no 4. Roots's blowers, with rolling bearing and gears

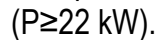

Assessment/Evaluation of manufacturing quality, according to this standard, consists in analysis of three zones:

- Zone no I. Compressors, which vibrations are within this zone, are considered as suitable for continuous exploitation without any restrictions.

- Zone no Il. Compressors, which vibrations are within this zone, have high values of vibration. In each individual case, it should be checked weather the measurements of vibrations allows for continuous exploitation taking into account designed and real work conditions for a particular device. In general, these compressors can be used by a particular time under the current conditions, until the inspection or repair procedure.

- Zone no III. Compressors, which vibrations are within this zone, are designated for repair, because their vibrations values are recognized as so high that can cause damage of a particular machine.

The numerical values assigned to the limits of zones do not be considered as the values guaranteed by the producer. These values have to be agreed between a producer and a client exploiting a compressor. However, these values give information which allows for excluding serious errors as well as unrealistic demands. In some cases, especially for untypical compressor (having special properties), other zone limit values (greater or lower) can be demanded. In such cases, it is necessary to obtain producer confirmation that the compressor can be safely exploited under higher vibrations' values. The exemplary limits of zones for an evaluation of the housing - for the approval measurements for the I-st group of compressors are shown in Tab. 1.

Choice of measurement bands for evaluation of compressors is different in comparison to the recommendations given in the standard PN- ISO-10816-1 (1995). The values - which is used for evaluation of a compressor - are the effective amplitude of vibration velocity for two bands - are:

- for the band A - lower limit of the filter is equal to $0.5 \mathrm{~Hz}$, whereas the upper limit is determined based on third characteristic harmonics for compressor elements and variables - like e.g.:

- frequencies of main gear, synchronous:

$$
f_{z}=f_{0} \cdot z
$$

where: $z$ - number of teeth of pinion,

- frequencies of belt gear:

$$
f_{k}=k \cdot\left(\pi \cdot f_{0} \cdot D_{s}\right) / l_{k}
$$

where: $k$ - number of belts, $D_{s}$ - pitch diameter of belt wheel (pulley), $l_{k}$ - belt length,

- frequency of co-operation screw rotors:

$f_{H}=f_{0} \cdot z_{H}$

where: $z_{H}-$ number of coils of the screw.

Tab. 1. Zones' limits for evaluation of compressors of the I-st group. Effective value of velocity $[\mathrm{mm} / \mathrm{s}]$

\begin{tabular}{|c|c|c|c|c|}
\hline Group & $\begin{array}{c}\text { Support } \\
\text { type }\end{array}$ & $\begin{array}{c}\text { Zone } \\
\text { type }\end{array}$ & $\begin{array}{c}\text { Measurement } \\
\text { band A }\end{array}$ & $\begin{array}{c}\text { Measurement } \\
\text { band B }\end{array}$ \\
\hline \multirow{3}{*}{ Group I } & \multirow{2}{*}{ Stiff } & $1 / I$ & 8.0 & 3.5 \\
\cline { 3 - 5 } & \multirow{2}{*}{ Flexible } & I/IIII & 12 & 4.5 \\
\cline { 3 - 5 } & & $1 / / I$ & 10.0 & 4.5 \\
\cline { 3 - 5 } & & $1 / / I I$ & 15.0 & 7.0 \\
\hline
\end{tabular}

The calculated third harmonic is rounded up according to the method given in the cited standard.

- for the B band, the lower limit of filter is equal to $0.5 \mathrm{~Hz}$, whereas the upper maximal value of this band is determined by means of the formula: $f_{g}=2.2 \cdot f_{0}$ which is rounded to $10 \mathrm{~Hz}$. (Example: if we calculate $f_{g}=56.7 \mathrm{~Hz}$, then we finally consider value $60 \mathrm{~Hz}$ ).

In case of diagnostics of technical state of exploited compressors, we have to consider the values of zone I/II multiplied by 1.25 for the warning limit, whereas for the alarm limit, one have to multiply the value of zone $\mathrm{ll} / \mathrm{ll}$ by 1.25 .

In case of diagnostics of oil compressors, the value of pick acceleration amplitude (0-Peak), within the band $0.5 \mathrm{~Hz}-5 \mathrm{kHz}$, should not exceed the limit 15g.

\subsection{Example of evaluation of technical state of screw compressor}

Screw compressor shown in Fig. 2, of parameters given in Tab. 2 , worked by one year from the date of its mounting in a particular factory.

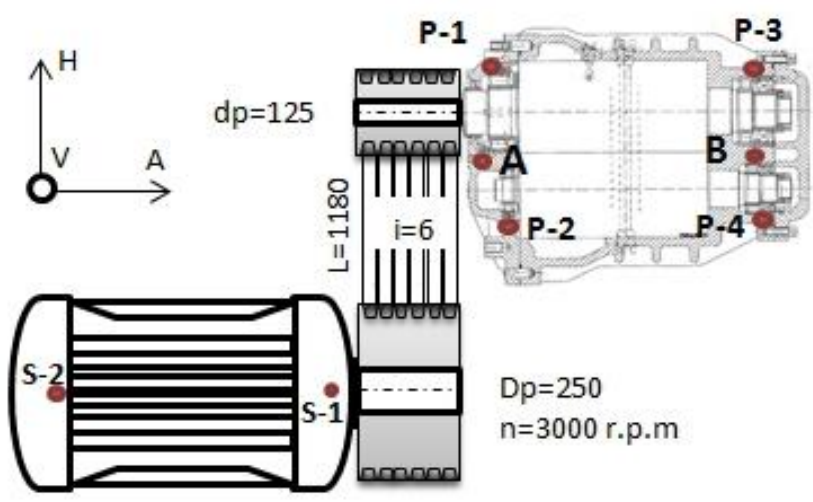

Fig. 2. Scheme of screw compressor which technical state was evaluated: rated power $55 \mathrm{~kW}$, rated rotations: $2995 \mathrm{rev} / \mathrm{min}$, maximal work pressure - 10 bar, number of coils of male screw: 4

Firstly, measurement bands $A$ and $B$ for a particular compressor have to be established. The rotational frequency of the input shaft is equal to $f_{0}=49.9 \mathrm{~Hz}$, for which the characteristic frequency of the compressor - calculated by means of formula (3) - 
is equal to $f_{H}=199.6 \mathrm{~Hz}$. The measurement band $\mathrm{A}$, calculated based on third harmonics is equal $3 \cdot f_{H}=599 \mathrm{~Hz}$, which is round up to the value $500 \mathrm{~Hz}$. The band is equal to $1000 \mathrm{~Hz}$.

The measurement band $\mathrm{B}$, for which the characteristic frequency is equal to $2,2 \cdot f_{o}=109.8 \mathrm{~Hz}$, but after rounding by $10 \mathrm{~Hz}$ - it is equal to $110 \mathrm{~Hz}$. The measurements of effective amplitudes of velocities, within the measurement bands $A$ and $B$, are listed in Tab. 2.

Tab. 2. Results of measurements of effective velocity amplitudes for the compressor

\begin{tabular}{|c|c|c|c|c|c|c|}
\hline \multirow{2}{*}{$\begin{array}{c}\text { Point } \\
\text { no }\end{array}$} & \multicolumn{2}{|c|}{ Band $\mathrm{A}(0.5 \mathrm{~Hz}-1000 \mathrm{~Hz})$} & \multicolumn{3}{c|}{ Band $\mathrm{B}(0.5 \mathrm{~Hz}-110 \mathrm{~Hz})$} \\
\cline { 2 - 7 } & $\mathrm{A}$ & $\mathrm{V}$ & $\mathrm{H}$ & $\mathrm{A}$ & $\mathrm{V}$ & $\mathrm{H}$ \\
\hline 1 & 2.3 & 2.2 & 2.3 & 0.4 & 0.2 & 0.3 \\
\hline 2 & 1.5 & 2.3 & 1.7 & 0.3 & 0.3 & 0.3 \\
\hline 3 & 10.3 & 2.6 & 4.8 & 0.7 & 0.8 & 0.5 \\
\hline 4 & 3.3 & 4.4 & 2.6 & 0.3 & 0.5 & 0.7 \\
\hline
\end{tabular}

The compressor could be qualified to group no II, for which - for band $A$, the zone I/II has value $10 \mathrm{~mm} / \mathrm{s}$, whereas the zone $I / / I I$ has value $15 \mathrm{~mm} / \mathrm{s}$. For band $B$, the zone $1 / /$ l has value $3 \mathrm{~mm} / \mathrm{s}$, whereas the zone $I / / I I I \mathrm{~mm} / \mathrm{s}$, respectively.

The level of vibrations of the compressor - for band $A-$ is qualified as belonging to the zone II. Based upon the analyses, the cause of occurrence of the essentially high values of vibration amplitudes - has to be checked (explained). The problem is connected with point no 3 in A direction. The procedure has to be performer in accordance with the demands of the standard. The decision should be taken: approval of the compressor for further exploitation (without any restrictions) or the exploitation should be restricted (terminated), until the moment when the prevention/repair actions will be performed.

\section{DIAGNOSTICS OF CHOSEN DAMAGES OF GEARS}

Sample test-stand with WiWiD system is presented in Fig. 3.

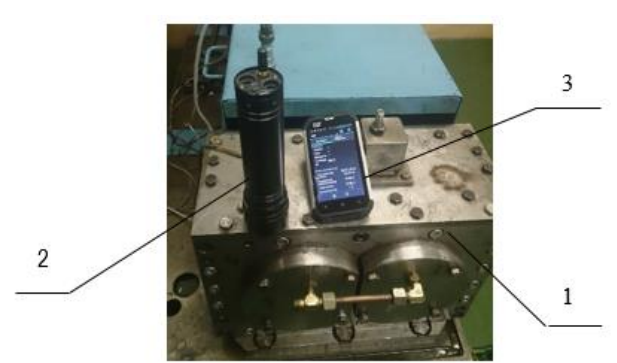

Fig. 3. Test stand: 1. investigated gear, 2. measurement device WiViD, 3. register-analytical device (smartphone)

Among versatile known diagnostics methods dedicated for detection of damages, in practice only the following methods are commonly applied: analysis of vibration spectrum and envelope spectrum. These methods were utilized for diagnostics of technical state of some strategic devices (installations) in the cement plant Dyckerhoff within a period of 10 years. The basics for determination of methodology of diagnostics of gear damages was the methodology described in book: Barkov and Barkowa, 1996; Choy et al., 1996; Feng and Ming, 2012; Feng and Zuo, 2013; Mirota et al., 2009; as well as an experience of the author achieved during diagnostics routines aiming for evaluation of technical state of devices in cement plants.
For each kind of damage, three types of symptoms were distinguished which indicate the particular kind of damage. These symptoms are as follows:

- band of frequency - in which an increase of the pick amplitude can be observed. We can recognize three band ranges for analysis - for the gears of general purpose of usage [9]: band of low frequency $0-300 \mathrm{~Hz}$, band of medium frequency $300-3000$ $\mathrm{Hz}$ and band of high frequency $>3000 \mathrm{~Hz}$,

- existence of particular order (sequence) of components in the spectrum of vibrations' accelerations,

- existence of particular order (sequence) of components in the envelope spectrum of vibrations.

In this method, it was assumed that the highest priority is assigned for a phenomenon of existence of a particular configuration of compounds in the envelope of vibrations' accelerations. The determination of this envelope is performed based on the adequate rules. Before determination of an envelope, the signal of vibrations should be subjected to the filtration procedure using upper-passing filter. Moreover, the cut frequency should be established in such a way - that for values of frequency above $f_{f}$ dominant compound should not be present. In practice, the value of cut band for a utilized filter is chosen from the interval $f_{f}=5 \mathrm{kHz} \div 12 \mathrm{kHz}$.

An analysis of methods of diagnostics for particular kinds of damages of a gear shows that one symptom can diagnose several different damages. This phenomenon causes in consequence a necessity of eye inspections of meshing's (mating gear elements) aiming for determination of damage kind.

\subsection{Examples of application of the method}

During the periodical diagnostics inspections of drive gears, which functional scheme is presented in Fig. 4 , it was observed that the alarm limits were crossed over - especially the alarm limits of estimates of pick amplitude of acceleration within the band $300 \mathrm{~Hz}-3000 \mathrm{~Hz}$.

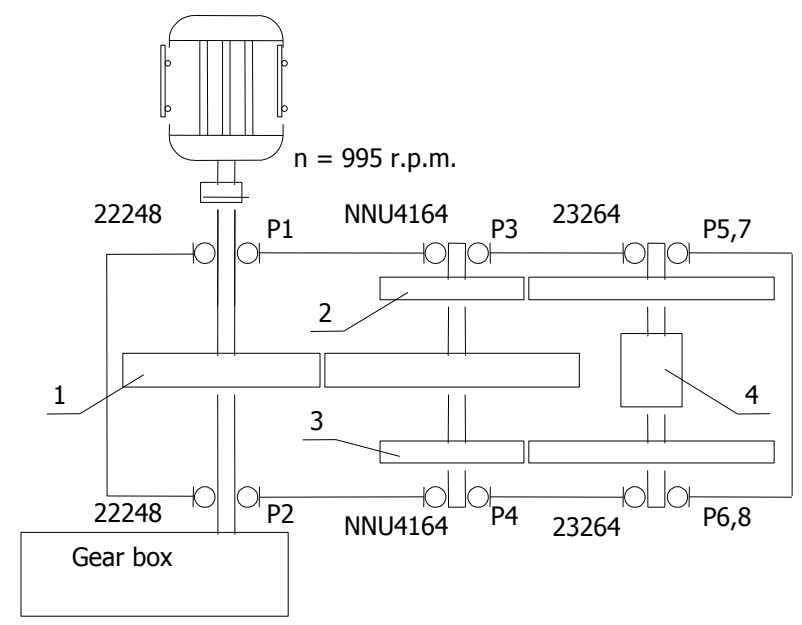

Fig. 4. Kinematical scheme of drive gear where displacement of measurement point is shown

In Fig. 5, trend of variations of pick amplitude of accelerations within the band $300 \mathrm{~Hz}-3000 \mathrm{~Hz}$ is shown.

Analysis of measurement results of pick amplitude within the band above $3 \mathrm{kHz}$ does not show any crossing over of the warning threshold (lack of increase of high frequency spectrum i.e. above 
$3 \mathrm{kHz}$ ). Spectrum of vibrations' accelerations - determinate in point $1 \mathrm{~V}-$ is shown, in Fig. 6.

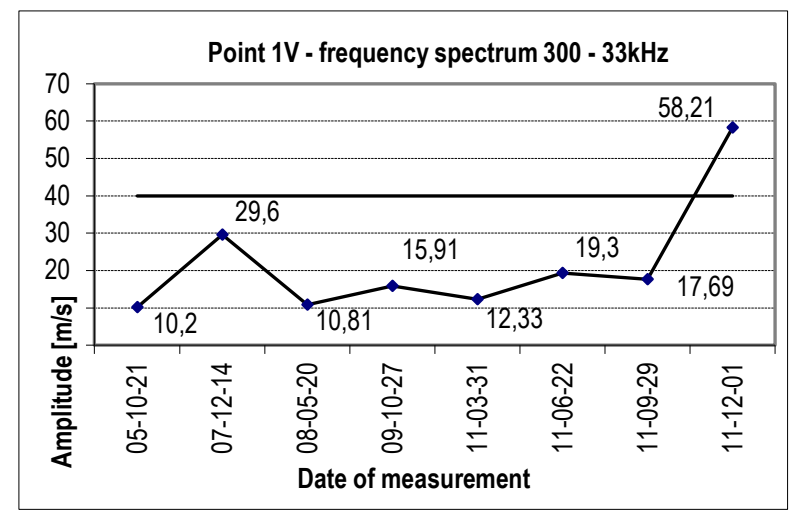

Fig. 5. Trend of changes of the pick amplitude of acceleration determined in measurement point no 1 in a vertical direction

In the discussed vibration spectrum, one can observed the components adequate for the meshing of the gear input stage. Moreover, there are side ribbons in the distance of the rotational frequency of the gear input shafts. In the envelope spectrum, show in Fig. 7 , determined in point $1 \mathrm{~V}$, one can observed the dominant components connected with the rotational frequency of the gear second shaft.

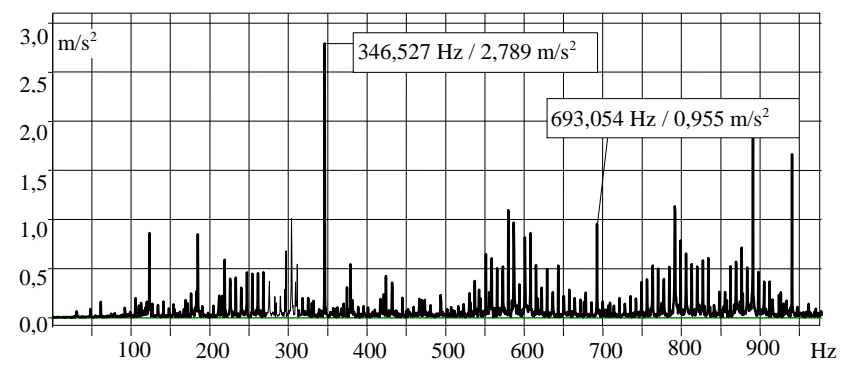

Fig. 6. Spectrum of accelerations - determine in point $1 \mathrm{~V}$ of gear

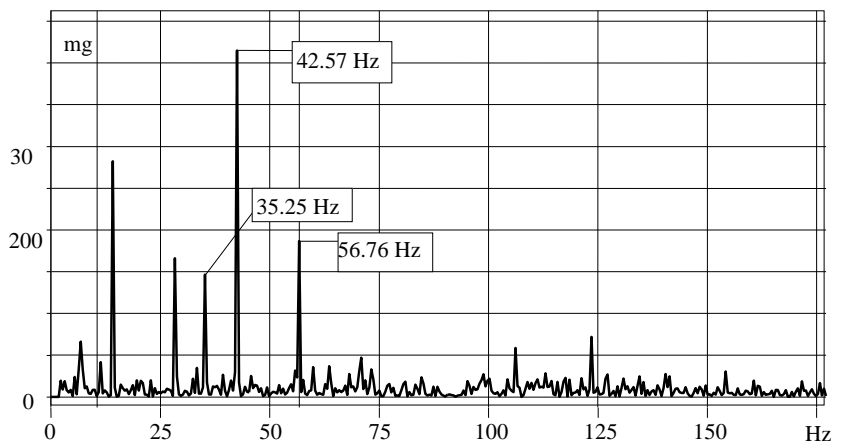

Fig. 7. Envelope spectrum determined in point $1 \mathrm{~V}$ determined within the band above $8 \mathrm{kHz}$

Harmonics (above $4(k>4))$ of rotational velocity of the second shaft in the envelope spectrum can be spotted. It means the defect of the gear wheel of the drive first stage.

The presented example show effectiveness of the diagnostics methods, based on an analysis of spectrum and envelope spectrum of the signal measured on the bearing housing - in which works the damaged element of gear. Based upon the long-year practice, it can be stated that the measurements of vibration signal on both bearing housings are needed for an effective diagnostics. In the described example, the phenomenon of crossing over of the warning pick amplitude within the band $300-3000 \mathrm{~Hz}$ - exists only on the bearing housings 1 and 2 . In other measurement point of the gear - this phenomenon was not observed.

\section{CONCLUSIONS}

In the present paper, two methods of diagnostics of the chosen machine types are discussed. The descriptions of their usage show complexity of the diagnostics process - where diagnosis of technical state of a device is done based upon the analysis of vibration signal (Farrahi et al., 20122; Rama and Dutta, 2012). Diagnostics methods dedicated to screw compressors are different than the common methods of evaluation of technical state of machine/device based on the standard ISO 10816 (1-7) as well as on its Polish equivalent PN-ISO 10816-1. Compressors belong to the group of simple machines, which are subjected to the mentioned standards, on contrary - gear belongs to the group of compound machines.

Compound machines cannot be evaluated upon the standard ISO 10816(1-7), due to the facts that versatile attempts of performance an evaluation of technical state utilizing these standards have not issued reliable information about their technical state. Therefore, diagnostics of compound machines have to be performed using other methods, e.g. via determination of individual diagnostics limit values, applying several different signal estimates.

The experimental investigations were carried out by means of the wireless measurement system WiViD. All the registered measurements were analyzed by means of own software routines.

\section{REFERENCES}

1. Barkov A. V., Barkova N. A. (1996), Diagnostics of gearings and geared couplings using envelope spectra methods, Proceedings of the 20th Annual Meeting of the Vibration Institute. Saint Louis, Missouri USA, 75-83.

2. Choy F. K., Polyshchuk V., Zakrajsek J. J., Handschuh R. F., Townsend D. P. (1996), Analysis of the effects of surface pitting and wear on the vibration of a gear transmission system, Tribology International, Vol. 29, No. 1, 77-83.

3. Farrahi G. H., Tirehdast M., Masoumi K. A. E., Parsa S., Motakefpoor M. (2011), Failure analysis of a gas turbine compressor, Engineering Failure Analysis, Vol. 18, No. 1, 474-484.

4. Feng Z., Zuo M.J . (2013), Fault diagnosis of planetary gearboxes via torsional vibration signal analysis, Mechanical Systems and Signal Processing, Vol. 36, No. 2, 401-421.

5. Feng Z. Z., Ming J. (2012), Vibration signal models for fault diagnosis of planetary gearboxes, Journal of Sound and Vibration, Vol. 331, No. 22, 4919-4939.

6. ISO 10816-1 (1995), Mechanical vibration - Evaluation of machine vibration by measurements on non-rotating parts - Part 1: General guidelines.

7. ISO 10816-3 (2009), Mechanical vibration - Evaluation of machine vibration by measurements on non-rotating parts - Part 3: Industrial machines with nominal power above $15 \mathrm{~kW}$ and nominal speeds between $120 \mathrm{r} / \mathrm{min}$ and $15000 \mathrm{r} / \mathrm{min}$ when measured in situ.

8. Mirota K., Tomaszewski J., Rysiński J. (2009), Diagnostics of scoring in gears, Solid State Phenomena, 144, 118-123.

9. Rama R. A., Dutta B. K. (2012), Vibration analysis for detecting failure of compressor blade, Engineering Failure Analysis, Vol. 25, 211-218.

10. VDI 3836 (2012), Measurement and evaluation of mechanical vibration of screw-type compressors and roots blowers, Addition to DIN ISO 10816-3. 